\title{
ARTICLE
}

Clinical Study

\section{A dynamic web-based decision aid to improve informed choice in organised breast cancer screening. A pragmatic randomised trial in Italy}

\author{
Anna Roberto ${ }^{1}$, Cinzia Colombo ${ }^{1}$, Giulia Candiani ${ }^{2}$, Roberto Satolli ${ }^{2}$, Livia Giordano ${ }^{3}$, Lina Jaramillo ${ }^{3}$, Roberta Castagno ${ }^{3}$, \\ Paola Mantellini ${ }^{4}$, Patrizia Falini ${ }^{4}$, Eva Carnesciali ${ }^{4}$, Mario Valenza ${ }^{5}$, Liliana Costa ${ }^{6}$, Cinzia Campari $^{7}$, Stefania Caroli ${ }^{7}$, \\ Roberto Cosimo Faggiano ${ }^{7}$, Lorenzo Orione ${ }^{8}$, Bruna Belmessieri $^{8}$, Vanda Marchiò ${ }^{8}$, Silvia Deandrea ${ }^{9}$, Anna Silvestri $^{9}$, Daniela Luciano $^{9}$, \\ Eugenio Paci ${ }^{10}$ and Paola Mosconi ${ }^{1}$
}

BACKGROUND: Improving the quality of information and communication is a priority in organised breast cancer screening and an ethical duty. Programmes must offer the information each woman is looking for, promoting informed decision-making. This study aimed to develop and evaluate a web-based dynamic decision aid (DA).

METHODS: A pragmatic randomised trial carried out in six regional organised screening programmes recruited women at the first invitation receiving DA or a web-based standard brochure (SB). The primary outcome was informed choice measured on knowledge, attitudes, and intentions. Follow-up period: 7-10 days. Secondary outcomes included participation rate, satisfaction, decisional conflict, and acceptability of DA.

RESULTS: Two thousand one hundred and nineteen women were randomised and 1001 completed the study. Respectively, $43.9 \%$ and $36.9 \%$ in the DA and SB reached the informed choice. The DA gave a 13-point higher proportion of women aware about overdiagnosis compared to SB $(38.3 \%$ versus $25.2 \%, p<0.0001)$. The percentage of women attending screening was the same: $84 \%$ versus $83 \%$. Decisional conflict was significantly lower in the DA group (14.4\%) than in the SB group (19.3\%).

CONCLUSION: DA increases informed choice. Complete information including the pros, cons, controversies, and overdiagnosis-overtreatment issues boost a woman's knowledge without reducing the rate of actual screening participation. CLINICAL TRIAL REGISTRATION: ClinicalTrials.gov number NCT 03097653.

British Journal of Cancer https://doi.org/10.1038/s41416-020-0935-2

\section{BACKGROUND}

Breast cancer (BC) is the leading cancer site among European women, with about 400,000 new cases every year. The incidence of $B C$ has continued to rise in almost all European countries in recent decades, while mortality rates have fallen in many countries, partly thanks to organised BC screening programmes. According with European Code against cancer, ${ }^{2,3}$ in Europe, BC screening programmes, under national health services, offer mammography every 2 years mainly to women aged $50-70$ years, with monitoring of performance and quality. ${ }^{4}$ In Italy in $2015 / 2016$, about six million women were invited and about $60 \%$ attended; recently in some regions, invitations were extended to 45-49- and 70-74-year-old women.,

Quality of information and communication and promotion of individual decision-making on mammography screening based on knowledge of its benefits and harms represent a priority. ${ }^{7}$ Information and campaigns about the benefits and harms of cancer screening have proved insufficient in many surveys, which have evaluated the contents of the leaflets or websites on women's knowledge. Most of them stress the benefits more than harms; false positive results and overdiagnosis-overtreatment, without quantitative estimates, are occasionally reported. ${ }^{8-10}$ Some studies have shown that many women confused early diagnosis with prevention, misunderstanding the value of screening. ${ }^{11,12}$

Information on mammography screening is a complex issue partly because of the scientific controversies on the evidence and quantification of the benefit and harm ratio, since a 2001 Cochrane Systematic review denied the impact on mortality of mammography screening and estimated high risks of overdiagnosis-overtreatment. $^{13}$ In 2010, European screening researchers assessed the published outcomes in terms of benefits and harms of the ongoing and oldest screening programmes. ${ }^{14}$ In the same year, the Independent UK Panel confirmed the

\footnotetext{
${ }^{1}$ Istituto di Ricerche Farmacologiche Mario Negri IRCCS, Milano, Italy; ${ }^{2}$ Zadig, Agenzia di Editoria Scientifica, Milano, Italy; ${ }^{3}$ SSD Epidemiologia e Screening - CPO Piemonte - AOU Città della Salute e della Scienza, Torino, Italy; ${ }^{4}$ SC Screening e Prevenzione Secondaria, Istituto per lo Studio, la Prevenzione e la Rete Oncologica - ISPRO, Firenze, Italy; ${ }^{5}$ UO Centro Gestionale Screening, ASP di Palermo, Palermo, Italy; ${ }^{6}$ U.O.S. Screening Mammografico, ASP di Palermo, Palermo, Italy; ${ }^{7}$ S.S. Screening Oncologici - Azienda Unità Sanitaria

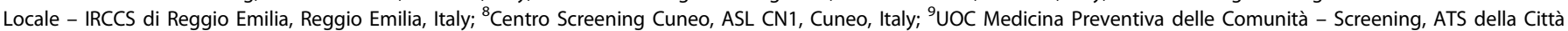
Metropolitana di Milano, Milano, Italy and ${ }^{10}$ Lega Italiana per la Lotta contro i Tumori, Sezione Firenze, Italy

Correspondence: Paola Mosconi (paola.mosconi@marionegri.it)
}

Received: 24 December 2019 Revised: 6 May 2020 Accepted: 26 May 2020

Published online: 17 June 2020 
evaluation of the efficacy of mammography screening. ${ }^{15}$ Nevertheless, there is still strong pressure for ending the mammography screening programmes ${ }^{15}$; in Switzerland in 2014 and in France in 2016, review and consultation reports have opened the debate again on the utility of BC screening programmes. ${ }^{16}$ An IARC monograph in 2002, updated in 2015, confirmed the validity of screening programmes, ${ }^{17}$ as well the new European guidelines. ${ }^{18}$ In 2013, the Cochrane systematic review was updated confirming the initial evaluation. ${ }^{19}$ However, this sharp debate has not put an end to the controversy.

Each woman should decide on the basis of experience and personal values, despite the individual invitation by the organised screening programmes. A decision aid (DA) that explains benefits and harms of screening better than the "regular" invitation letter is suggested by the European recommendations, ${ }^{18}$ according with a Cochrane review on DAs in screening decisions. ${ }^{20}$ DAs improve patients' knowledge, clarify values, reduce decisional conflict and encourage women to take a more active role in decision-making without anxiety. ${ }^{20}$

The Donnainformata-Mammografia project (informed women mammography) was designed to develop and evaluate a webbased dynamic DA in a pragmatic randomised trial, i.e. as part of organised mammography screening programmes' practice. ${ }^{21}$ The aim was to compare DA with a web-based standard static brochure (SB).

\section{METHODS}

Six regional organised screening programmes invited women eligible for a first invitation-aged $>50$ years in 4 screening programmes and aged $>45$ years in 2 , without personal history of $\mathrm{BC}$-with an official letter sent about 30 days before the screening invitation. According to the protocol published elsewhere, ${ }^{21}$ three programmes participated since the beginning, three additional programmes joined the study later due to the difficulties to achieve the required sample size.

Development of the DA and SB

The contents and layout of the DA were developed after a literature review ${ }^{17,22-24}$, a collection of screening information materials, a focus group phase including 18 women, and 4 indepth semi-structured interviews (data not reported). We included women aged 45-54 years who had participated in a screening programme in the previous 6 months not having a positive result. Women with a personal or family history of $\mathrm{BC}$ were excluded. The aim was to gather information needs, knowledge and attitudes towards BC screening and comments on a draft of the home page of the DA including the main topics covered in the tool. A convenience sample of these women was further interviewed to provide feedback on pre-final version of the DA; findings guided the wording, the contents and the layout.

Scientific evidence was based on the Euroscreen ${ }^{14}$ and Independent UK Panel. ${ }^{25}$ Development of DA started from the criteria of the International Patient Decision Aid Standards Collaboration. ${ }^{26}$

In the homepage of the DA, a nudging-like approach was used to highlight four main sections: What is BC? What is mammography screening? What are its benefits and harms? What results can be expected from mammography screening? Women were free to decide which sections to access and to move to other pages linked from the homepage.

Topics were described in plain language and the benefit/harm balance was defined on the basis of literature. ${ }^{14,15,25}$ The information covered controversial issues such as false positive results and overdiagnosis-overtreatment (www.donnainformatamammografia.it).

The SB was assembled on the basis of brochures used in the participant-organised screening programmes of Turin, Florence and Palermo (Supplementary File 1). Comparative information regarding the DA and SB is reported in Table 1. DA provided a module listing issues and concerns that can affect screening decision, and each woman was asked to state the importance of each item (Supplementary File 2).

Any time, navigating the DA or SB, a woman could decide if she had enough information and leave the platform.

Assessment of the impact of the DA

Women were selected from the computerised demographic list of the screening programmes. Each eligible woman received an invitation to participate and a personal code number to log into the platform. After signing the informed consent form and compiling a baseline questionnaire, women were randomised to the DA or SB in a 1:1 ratio. After 7-10 days, women were contacted via email or short message service and invited to complete a follow-up questionnaire. Every 3 days, a reminder was sent to non-responders until the scheduled mammography date.

To define the outcome, we start from a Cochrane review, ${ }^{20}$ and we reviewed literature including randomised controlled trials on BC screening DAs published from 2012 to 2016.

The primary outcome was informed choice, assessed as a dichotomous variable: a woman with adequate knowledge ( $>8 / 13$ correct answers) and consistent attitude and intention was considered as expressing informed choice. ${ }^{22-24,27}$ Secondary outcomes were participation rate, satisfaction on information, decisional conflict, $^{28}$ time spent on the platform and the acceptability of DA (Supplementary File 3).

Statistical analysis

A sample of 816 women was required (5\% alpha, $80 \%$ power). ${ }^{21}$ For the primary analysis, done on an intention-to-treat basis in accordance with the protocol, all the women randomised, compliant to follow-up, were included in the final analysis. ${ }^{21}$ The proportions of women were compared with a chi-square test (two-sided, $P<0.05)$. A $t$ test was used for continuous endpoints (two sided, $P<0.05$ ). Analyses were done with the SAS statistical software, version 9.4.

\section{RESULTS}

A total of 21,014 women were invited (Fig. 1), with a recruitment phase lasting 15 months, from September 2017 to December 2018. Among the organised BC screening programmes, the number of women contacted ranged from 1655 to 7278 . Finally, 2119 women signed the informed consent form, completed the baseline questionnaire and were randomised (randomised sample). Of these, 1001 completed the follow-up questionnaire (final sample).

Table 2 illustrates the characteristics of women; there was no significant imbalance. Most women had an Italian citizenship, were married, employed and used internet sporadically for health information. About two-thirds had relatives and/or acquaintances who had received a diagnosis of $\mathrm{BC}$, about $70 \%$ had a previous mammography and most (70\%) perceived having a BC risk in line with women of the same age.

Figure 2 shows the proportion who reached the informed choice: $43.9 \%(207 / 472)$ and $36.9 \%(195 / 529)$ in the DA and SB arms, respectively $(P=0.0328)$. At the baseline questionnaire, $23.1 \%$ in the DA and $18.3 \%$ in the SB group $(P=0.0694)$ had adequate knowledge and consistent attitude and intention, meaning an increase in informed choice of $20.8 \%$ versus $18.6 \%$, respectively, in the DA and SB arms.

Details of the primary outcome shows that information about screening and benefits was generally good, whereas only about $65 \%$ recognised the possibility of a false negative result (interval cancer). The DA gave a 13-point higher proportion of women aware about overdiagnosis compared to the SB (38.3\% versus 
Table 1. Comparison of the decision aid and standard brochure.



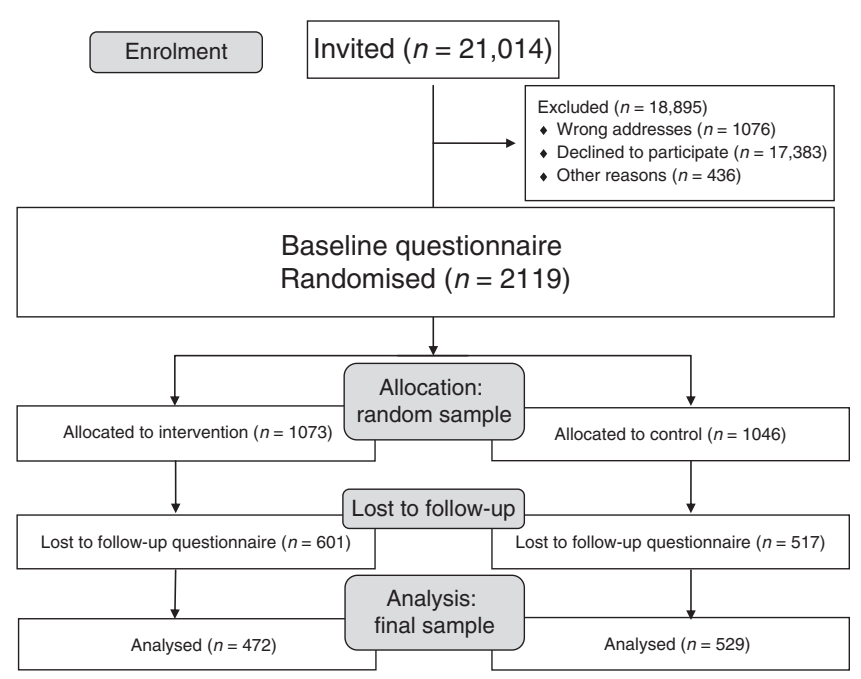

Fig. 1 Consort flow diagram: overview of trial participation.
25.2\%, $P<0.0001)$. Overtreatment had similar frequencies (37.7\% versus $26.6 \%, P=0.0002$ ). Information about controversies in mammography screening was poor in the SB arm where this information was not given and limited in the DA $(11.0 \%$ versus $27.2 \%, P<0.0001)$. On numerical items, the DA women had a worse idea of the frequency of BC mortality for women in the same age group, both with and without mammography screening programmes (DA $21.1 \%$ versus SB $25.6 \%, P=0.0944$ ). The SB group responded more correctly about the estimates of overdiagnosis (DA $19.6 \%$ versus SB 26.4, $P=0.0117$ ). Attitude and intention towards $B C$ screening were high in both the groups (>90\%; Table 3 ).

Regarding secondary outcomes (Table 4), a large proportion of women had no decisional conflict, and it was significantly lower in the DA group (14.4\%) than in the SB group (19.3\%) $(P=0.0403)$. In both the groups, most women $(>90 \%)$ considered the information as enough and clear, and they would recommend it to other women. The information conveyed was mainly considered in favour of BC screening (around 65\% in both the groups) and useful for deciding (around $70 \%$ in both the groups). Some information regarding benefits was considered new. The 
percentage of women attending $B C$ screening was the same in the

Table 2. Main characteristics of the women involved in the study.

\begin{tabular}{|c|c|c|c|c|}
\hline & \multicolumn{2}{|c|}{ Randomised sample } & \multicolumn{2}{|c|}{ Final sample } \\
\hline & $\begin{array}{l}\text { Decision } \\
\text { aid, } \\
N=601\end{array}$ & $\begin{array}{l}\text { Standard } \\
\text { brochure, } \\
N=517\end{array}$ & $\begin{array}{l}\text { Decision } \\
\text { aid, } \\
N=472\end{array}$ & $\begin{array}{l}\text { Standard } \\
\text { brochure, } \\
N=529\end{array}$ \\
\hline & $N(\%)$ & $N(\%)$ & $N(\%)$ & $N(\%)$ \\
\hline Age (in years), mean (SD) & $49.7(3.1)$ & $49.7(3.3)$ & $49.0(3.0)$ & $49.2(3.3)$ \\
\hline \multicolumn{5}{|c|}{ Education } \\
\hline Elementary & $9(1.5)$ & $8(1.6)$ & $2(0.4)$ & $4(0.8)$ \\
\hline Lower middle & $103(17.2)$ & $109(21.2)$ & $69(14.7)$ & $71(13.5)$ \\
\hline Higher middle & $297(49.5)$ & $229(44.5)$ & $234(49.8)$ & $272(51.7)$ \\
\hline Degree & 179 (29.8) & $157(30.5)$ & $156(33.2)$ & $170(32.3)$ \\
\hline Other & $12(2.0)$ & $12(2.3)$ & $9(1.9)$ & $9(1.5)$ \\
\hline \multicolumn{5}{|l|}{ Nationality } \\
\hline Italian & $579(96.5)$ & $498(96.7)$ & $458(97.4)$ & $506(96.2)$ \\
\hline \multicolumn{5}{|l|}{ Marital status } \\
\hline Married or cohabitant & $432(72.1)$ & $370(71.8)$ & $342(72.8)$ & $386(73.4)$ \\
\hline \multicolumn{5}{|l|}{ Employment status } \\
\hline Paid work & $466(77.8)$ & 405 (78.6) & $366(77.9)$ & $425(80.8)$ \\
\hline \multicolumn{5}{|l|}{ Use internet for health info } \\
\hline Never & $160(26.7)$ & $136(26.4)$ & $128(27.2)$ & $111(21.0)$ \\
\hline A few times/month & $289(48.2)$ & $260(50.5)$ & $230(48.9)$ & $271(51.5)$ \\
\hline At least once/week & $54(9.0)$ & $48(9.3)$ & $49(10.4)$ & $44(8.4)$ \\
\hline Several times/week & $37(6.2)$ & $28(5.4)$ & $29(6.2)$ & $43(8.2)$ \\
\hline \multicolumn{5}{|l|}{ Daily } \\
\hline $\begin{array}{l}\text { Acquaintance/family } \\
\text { with BC (yes) }\end{array}$ & $396(66.0)$ & $347(67.4)$ & $331(70.4)$ & $380(72.2)$ \\
\hline Previous tumours (yes) & $43(7.2)$ & $32(6.2)$ & $24(5.1)$ & $38(7.3)$ \\
\hline \multicolumn{5}{|l|}{ Perceived risk of $B C$} \\
\hline Much lower & $26(4.4)$ & $24(4.7)$ & $24(5.1)$ & $17(3.2)$ \\
\hline A bit lower & $47(7.9)$ & $38(7.4)$ & $23(4.9)$ & $45(8.6)$ \\
\hline $\begin{array}{l}\text { About the same as } \\
\text { average women }\end{array}$ & $434(72.6)$ & $373(72.6)$ & $347(74.0)$ & 381 (72.6) \\
\hline A bit higher & $75(12.5)$ & $61(11.9)$ & $61(13.0)$ & $67(12.8)$ \\
\hline Much higher & $16(2.7)$ & $18(3.5)$ & $14(3.0)$ & $15(2.9)$ \\
\hline $\begin{array}{l}\text { Previous } \\
\text { mammography (yes) }\end{array}$ & $430(71.5)$ & $355(68.7)$ & $311(65.9)$ & $372(70.3)$ \\
\hline $\begin{array}{l}\text { Participation in faecal } \\
\text { occult blood test } \\
\text { screening (yes) }\end{array}$ & $101(16.9)$ & $93(18.1)$ & 84 (17.9) & $106(20.2)$ \\
\hline $\begin{array}{l}\text { Participation in Pap test } \\
\text { screening (yes) }\end{array}$ & $462(77.1)$ & $418(81.2)$ & $357(76.0)$ & $410(78.2)$ \\
\hline
\end{tabular}

Some differences are due to missing data.

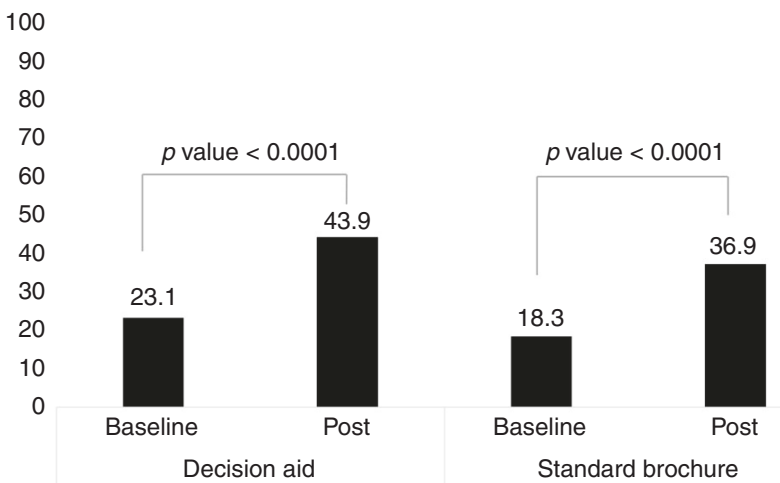

Fig. 2 Informed choice: main outcome of the study. two groups: $84 \%$ of women surfing the DA versus $83 \%$ for women receiving the SB $(P=0.6537)$. On average, 4.8 (SD 4.2) pages were visited on the DA; women spent more time on the pages "The main risk and protective factors" and "How are the rates of specific mortality reduction and overdiagnosis measured?". The median time spent, considering a mean of 215 words per screen, ranged between 97 and $16 \mathrm{~s}$. According to the number of women who visited each page, besides the homepage, the most visited pages were related to pro and cons, quality and results of BC screening programmes; what happens at each round of screening; what is $\mathrm{BC}$ and related treatment; and the balance between benefits and harms of $B C$ screening.

According to the value each woman gave to the items in their decision-making process, cancer mortality, breast conservation, risk of developing a $\mathrm{BC}$ and quality of the organised screening programmes are the main factors judged as important in the decision to participate (or not) in mammography screening. Harms and controversies seem not to influence this choice (Supplementary File 4, Fig. 1).

\section{DISCUSSION}

This pragmatic trial shows that the DA increases informed choice compared to the $\mathrm{SB}$, without reducing the rate of screening participation. The attitude towards screening and intention to participate were extremely positive at baseline- $>90 \%$ - and did not change at follow-up assessment. Most women had already had a mammography and were unaware of the current controversies. These findings are in line with the focus groups held at the beginning of the project showing a positive attitude towards screening.

The DA offered detailed qualitative and quantitative information on benefits, harms and controversies, which are rarely presented in the standard materials received by women. We provided these topics at the same time making explicit our position towards the national health BC screening programme, to be transparent and consistent with our position as promoters.

At baseline, one-third of the women knew about overdiagnosis, whereas $<15 \%$ knew the meaning of overtreatment. A higher frequency of women in the DA group correctly responded on overdiagnosis-overtreatment. However, the proportion was low compared to the proportion of women responding correctly (both in $\mathrm{DA}$ and $\mathrm{SB}$ ) to the false positive question. As seen during the focus groups, overdiagnosis-overtreatment issues are complex, sometimes obscure and not intuitive-as shown in other studies too. ${ }^{29,30}$

More women responded correctly to the false positive question than to the false negative one (both in DA and in SB). This is in line with the findings by Perez-La Casta ${ }^{31}$ in the InforMa trial conducted in a similar screening programme setting in Spain. Considering other studies on DAs and perception of women towards screenings, ${ }^{32}$ the risk of false positive results is known by women and underlined by information conveyed to women more often than the false negative one. The psychological impact of a false positive result can be severe for a woman, compared to a false negative result that is difficult to define on a single basis. Furthermore, in BC screening the false negative rate is lower than the false positive one.

The numerical items had a lower frequency of correct responses than conceptual items; however, the numerical item on overdiagnosis-overtreatment had correct responses from $64.0 \%$ in the DA group and $69.7 \%$ in the SB group. The SB presented fewer numerical information than the DA and was accessible on one printable page. This may have facilitated a correct answer.

From the baseline in both the groups, there was a significant increase in the proportion of women's knowledge, which was the 
Table 3. Details of primary outcome.

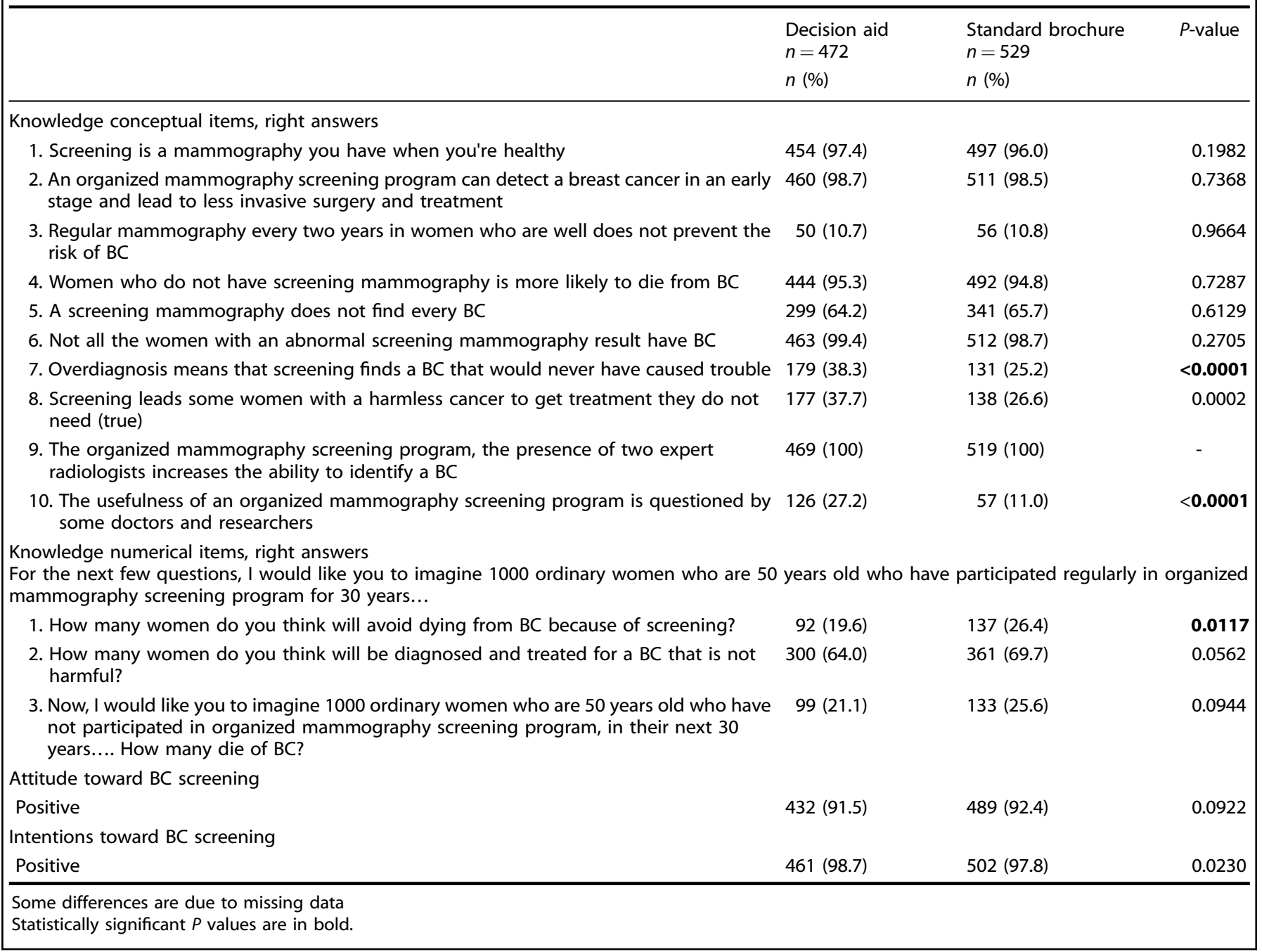

dimension that mainly influenced the informed choice. It might also indicate that the $S B$, a mix of brochures used in three $B C$ screening programmes, is a potentially useful tool to improve knowledge and may be more informative than the leaflets of the different Italian screening programmes. The DA and SB reported comparable information with different details according to the ethical duty to convey the same standard of information that women generally receive within screening programmes.

The time spent surfing the DA was limited though each section was short (77-416 words). The level of satisfaction with the information was high in both arms, hitting our goal to produce material matching the interest in being informed and our aim to present complex information in a straightforward, user-friendly way.

Women perceived the $D A$ and $S B$ as being in favour of $B C$ screening, despite the fact that the DA illustrated pros and cons, overdiagnosis-overtreatment and presented different ways to assess the benefit-harm ratio (controversies). This might reflect the setting in which the study was conducted-i.e. within screening programmes.

Women receiving the DA reported less decisional conflict than the SB group; they felt better supported and advised about their choice and more confident about it.

These results match the findings of reviews showing that DA about BC screening can improve knowledge and promote informed decision-making. ${ }^{33}$ Recent clinical trials also showed that complete information positively influences the informed choice.

Hersch et al. ${ }^{22}$ recruited women aged $48-50$ years by telephone in a community-based trial to compare two kinds of DA, differing in including or not information on overdiagnosis-overtreatment. The comparison group received a high standard of information, more than usual leaflets. The authors concluded that information on overdiagnosis increased the number of women making an informed choice and that significantly fewer women expressed positive attitudes towards screening.

Reder and Kolip ${ }^{34}$ compared an SB with a new DA in 50-year-old women invited to participate in a BC organised screening programmes. Both groups had a very positive attitude towards screening. The results suggested that the DA increased the level of informed choice and knowledge and reduced decisional conflict.

Perez-La Casta ${ }^{31}$ in the InforMa trial assessed the effect of receiving information about benefits and harms of $\mathrm{BC}$ screening on informed choice in women likely to be invited in organised programmes. Spanish 50-year-old women were randomly selected and allocated to a DA or an SB where harms were not mentioned. Similarly to our study, about $80 \%$ of the Spanish participants had had a previous mammogram. The study shows a strong increase in the number of women who made an informed choice. Intention to be screened was high in both the groups with no difference in screening participation. 
Table 4. Secondary outcomes.

\begin{tabular}{|c|c|c|c|}
\hline & $\begin{array}{l}\text { Decision aid, } \\
N=472 \\
N(\%)\end{array}$ & $\begin{array}{l}\text { Standard } \\
\text { brochure, } \\
N=529 \\
N(\%)\end{array}$ & $P$ value \\
\hline $\begin{array}{l}\text { Participation in BC screening } \\
\text { (yes) }\end{array}$ & $376(84.1)$ & $416(83.0)$ & 0.6537 \\
\hline \multicolumn{4}{|l|}{ Satisfaction with information } \\
\hline $\begin{array}{l}\text { Was there enough } \\
\text { information }\end{array}$ & & & 0.0162 \\
\hline Too much & $17(3.6)$ & $6(1.2)$ & \\
\hline Too little & $19(4.1)$ & $31(6.0)$ & \\
\hline Fair & $432(92.3)$ & $480(92.8)$ & \\
\hline $\begin{array}{l}\text { Was the information on } \\
\text { benefit new to you? }\end{array}$ & & & 0.1000 \\
\hline All or almost all & $32(6.8)$ & $53(10.3)$ & \\
\hline Some & 337 (71.9) & $345(66.7)$ & \\
\hline None & $100(21.3)$ & $119(23.0)$ & \\
\hline $\begin{array}{l}\text { Was the information on } \\
\text { harm new to you? }\end{array}$ & & & 0.0671 \\
\hline All or almost all & 49 (10.5) & $51(9.9)$ & \\
\hline Some & $288(61.4)$ & $285(55.1)$ & \\
\hline None & $132(28.1)$ & $181(35.0)$ & \\
\hline Was the information clear? & & & 0.4759 \\
\hline All or almost all & $434(92.5)$ & $472(91.3)$ & \\
\hline Some & $35(7.5)$ & $45(8.7)$ & \\
\hline The information seemed... & & & 0.3702 \\
\hline In favour of screening & $296(63.1)$ & $342(66.1)$ & \\
\hline Balanced & $173(36.9)$ & $174(33.7)$ & \\
\hline Against screening & & $1(0.2)$ & \\
\hline Did it help you to decide? & & & 0.8499 \\
\hline Yes & $330(70.4)$ & $360(69.6)$ & \\
\hline Not much & $108(23.0)$ & $118(22.8)$ & \\
\hline No & $31(6.6)$ & $39(7.5)$ & \\
\hline $\begin{array}{l}\text { Would you recommend it } \\
\text { to other women? }\end{array}$ & & & 0.2129 \\
\hline Yes & $454(96.8)$ & $507(98.1)$ & \\
\hline Not much & $15(3.2)$ & $9(1.7)$ & \\
\hline No & & $1(0.2)$ & \\
\hline \multicolumn{4}{|l|}{$\begin{array}{l}\text { Was the controversy new } \\
\text { to you? }\end{array}$} \\
\hline All or almost all & $70(15.0)$ & & \\
\hline Some & $338(72.0)$ & & \\
\hline None & $61(13.0)$ & & \\
\hline \multicolumn{4}{|l|}{ Decisional conflict } \\
\hline $\begin{array}{l}\text { Decisional conflict } \\
\text { (score } \geq 3 \text { ) }\end{array}$ & $68(14.4)$ & $102(19.3)$ & 0.0403 \\
\hline No decisional conflict & $404(85.6)$ & $427(80.7)$ & \\
\hline \multicolumn{4}{|l|}{ Median time spent, $\mathrm{s}$} \\
\hline Home page & 42 & & \\
\hline Mammography screening & 22 & & \\
\hline $\begin{array}{l}\text { Pros/cons of } \\
\text { mammography screening }\end{array}$ & 55 & & \\
\hline $\begin{array}{l}\text { What happens in the next } \\
30 \text { years? }\end{array}$ & 56 & & \\
\hline Age recommended & 30 & & \\
\hline Radiation risks & 31 & & \\
\hline & 41 & & \\
\hline
\end{tabular}

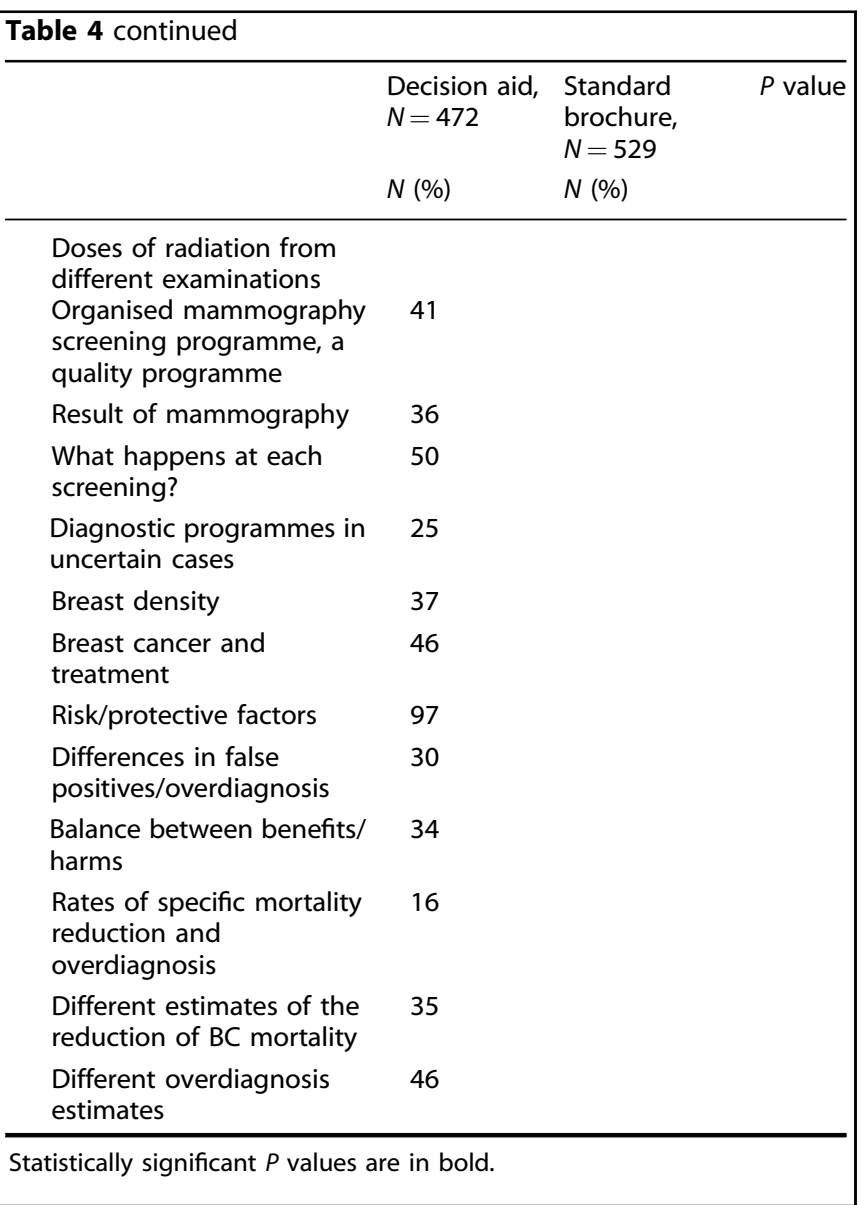

It is hard to compare the results of these studies because of different control leaflets used, differences in how the primary outcome was measured and in setting, cultural environment, type of information conveyed, and control arm. However, increase in knowledge and informed choice always emerged.

Like the InforMa ${ }^{31}$ and Reder ${ }^{34}$ studies, our study was part of organised BC screening programmes, facilitating the adoption of the DA in standard practice, in addition to well-balanced informative leaflets, as the one developed within our study.

Being able to conduct this pragmatic trial in the context of the service screening is an important achievement. ${ }^{35}$ Procedures were integrated in the invitation system, contacting women in a userfriendly way and not overloading the staff involved. Organised screening has high potential for complex research investigations, facilitating informed consent and respecting women's privacy. Outside a research context since the registration on the platform and answer to questionnaires will no longer be necessary, the DA use could be more feasible, at least in the younger age groups (45-54 years).

The DA and SB arms were balanced according to the randomisation design, the characteristics of final sample remaining balanced even considering the dropouts.

The information in the DA was iteratively revised on the basis of the best evidence available by a multidisciplinary group including experts in communicating health issues, experts with decisional tools, BC screening multi-professional scientific societies, epidemiologists and representatives of consumers and patients.

This study has several limitations. First, considering the sample size, the response rate was lower than expected, and there were about $50 \%$ dropouts. We invited more women than expected $(21,014$ versus 8160$)$. This high proportion of dropouts could be 
also due to scarce attention of women to comply with this type of study, suggesting the need for careful review of the recruitment process. Participating women had a high level of education, which limits the generalisability of findings, in agreement with other studies. $^{22,31,34}$ Most of the participants had already had a mammography before the invitation to the organised screening programme. This suggests that many had already received information that could have fostered the attitude and intention reported in this study. Finally, in order to participate, women had to have basic information technology skills. It is likely that technical developments will offer more user-friendly tools for sharing information, increasing users' knowledge and facilitating decision-making in complex healthcare areas, such as mammography screening. However, to reduce the imbalances between population subgroups, it will be essential to identify alternative strategies and means to effectively reach women who do not use computers. As recently reported in the guidelines of the European commission, DAs are recommended taking account of the cultural contexts and literacy levels. ${ }^{18}$

Experience in the construction of a flexible, simple and accurate DA offers a valuable opportunity to reach many women. This will be possible in the near future using smartphones, and work in that direction is needed.

Complete information including the pros, cons, controversies and overdiagnosis-overtreatment issues boost a woman's knowledge without her losing interest in BC screening. Attitudes towards screening are very positive, and women do not change them because of knowledge of the benefit-harm ratio when mammography screening is proposed as an evidence-based, advantageous practice organised in the framework of the National Health Service.

Our findings, in line with a general consensus on the right to have access to correct information, ${ }^{7}$ confirm that a screening service has the duty to provide the best possible information about benefit and harms of screening to facilitate decision-making and ensure informed consent by women. ${ }^{36}$

\section{ACKNOWLEDGEMENTS}

The authors thank the Members of Steering Committee: Vania Galli, AITERS Associazione Italiana Tecnici di Radiologia Senologica; Daniele Caldara, Altroconsumo; Mario Taffurelli, ANISC - Associazione Nazionale Italiana Senologi Chirurghi; Davide Petruzzelli, Associazione La Lampada di Aladino; Elisabetta Sestini, Europa Donna Italia; Paola Zimmermann, Federazione per il Sociale e la Sanità della Provincia Autonoma di Bolzano e Rete Nord-Est; Valter Torri, Istituto di Ricerche Farmacologiche Mario Negri IRCCS, Milano; Alberto Donzelli, Servizio di educazione all'appropriatezza e medicina basata sulle evidenze, ASL Città di Milano; Francesca Russo, Servizio Sanità Pubblica e Screening, Regione Veneto; Serena Apice, SIMG Società Italiana di Medicina Generale e delle cure primarie; Francesco Sardanelli, SIRM - Società Italiana Radiologia Medica. For their activity in the project, the authors thank Gianna Costa, AppCademy - Florence, Nico Leonardo and Giancarlo Pastore (UOC Medicina Preventiva delle Comunità - Screening, ATS della Città Metropolitana di Milano). We are grateful to J. D. Baggott for editing the manuscript. This project won a competitive grant of Italian Association for Cancer Research IG2015-17274.

\section{AUTHOR CONTRIBUTIONS}

Conception and design: P. Mosconi, R.S., E.P., and L.G. Provision of study material: A.R., C. Colombo, G.C., P. Mosconi, E.P., M.V., and P. Mantellini. Collection and assembly of the data: L.J., R.C., P. Mantellini, P.F., E.C., M.V., L.C., C. Campari, S.C., R.C.F., L.O., B.B., V.M., S.D., A.S., and D.L. Data analysis and interpretation: A.R., C. Colombo, P.M., E.P., R.S., G.C., L.G., L.J., P. Mantellini, C. Campari, S.D., and M.V. Paper writing: P. Mosconi, A.R., C. Colombo, E.P., L.G., and S.D. Final approval of the paper: all authors.

\section{ADDITIONAL INFORMATION}

Ethics approval and consent to participate The protocol and study documents were approved by the following ethics committee: Comitato Etico Fondazione IRCCS Istituto Neurologico Carlo Besta, Comitato Etico Fondazione IRCCS Ca' Granda Ospedale Maggiore Policlinico, Comitato Etico Area Vasta Centro AOUC Azienda Ospedaliero-Universitaria Careggi, Comitato Etico di Area Vasta Emilia Nord di Reggio
Emilia, Comitato Etico Interaziendale dell'AO S. Croce e Carle di Cuneo, Comitato Etico Palermo 1 and Comitato Etico Interaziendale A.O.U. Città della Salute e della Scienza di Torino. Written informed consent was obtained. This study was designed and conducted in compliance with the principles of the Declaration of Helsinki.

Consent for publication Informed consent was obtained from all. This report does not contain any individual person's information.

Data availability Data supporting the results will be provided on public websites or archives.

Competing interests A.R., C. Colombo and P. Mosconi report grants from Italian Association for Cancer Research, competitive grant no. IG2015-17274, during the conduct of the study; G.C., R.S. and E.P. report grants from Mario Negri IRCCS Institute, during the conduct of the study; L.G. reports grants from Mario Negri IRCCS Institute and Gisma (Italian group that organised mammography screening) during the conduct of the study; P. Mantellini and M.V. report grants from Gisma (Italian group that organised mammography screening) during the conduct of the study. Authors not named here have disclosed no conflict of interest.

Funding information This project won a competitive grant of Italian Association for Cancer Research IG2015-17274.

Supplementary information is available for this paper at https://doi.org/10.1038/ s41416-020-0935-2.

Publisher's note Springer Nature remains neutral with regard to jurisdictional claims in published maps and institutional affiliations.

\section{REFERENCES}

1. Ferlay, J., Colombet, M., Soerjomataram, I., Dyba, T., Randi, G., Bettio, M. et al. Cancer incidence and mortality patterns in Europe: estimates for 40 countries and 25 major cancers in 2018. Eur. J. Cancer 103, 356-387 (2018).

2. Armaroli, P., Villain, P., Suonio, E., Almonte, M., Anttila, A., Atkin, W. S. et al. European Code against Cancer, 4th Edition: cancer screening. Cancer Epidemiol. 39 (Suppl 1), S139-S152 (2015).

3. IARC. When should I participate in breast cancer screening? https://cancer-codeeurope.iarc.fr/index.php/en/ecac-12-ways/screening-recommandation/breast-cancerscreening/229-participate-in-breast-cancer-screening (2016). Accessed 1 Apr 2020.

4. Basu, P., Ponti, A., Anttila, A., Ronco, G., Senore, C., Vale, D. B. et al. Status of implementation and organization of cancer screening in The European Union Member States-summary results from the second European screening report. Int. J. Cancer 142, 44-56 (2018).

5. Osservatorio Nazionale Screening. Lo screening mammografico. https://www. osservatorionazionalescreening.it/content/lo-screening-mammografico (2018) Accessed 1 Apr 2020.

6. Bucchi, L., Ravaioli, A., Baldacchini, F., Giuliani, O., Mancini, S., Vattiato, R. et al. Annual mammography at age 45-49 years and biennial mammography at age 50-69 years: comparing performance measures in an organised screening setting. Eur. Radiol. 29, 5517-5527 (2019).

7. European Union. Council recommendation of 2 December 2003 on cancer screening. L 327/34. https://ec.europa.eu/jrc/sites/jrcsh/files/2_December_2003\% 20cancer\%20screening.pdf (2003). Accessed 1 Apr 2020.

8. Gotzsche, P. C., Hartling, O. J., Nielsen, M., Brodersen, J. \& Jorgensen, K. J. Breast screening: the facts-or maybe not. BMJ 338, b86 (2009).

9. Jorgensen, K. J. \& Gotzsche, P. C. Presentation on websites of possible benefits and harms from screening for breast cancer: cross sectional study. BMJ 328, 148 (2004).

10. Slaytor, E. K. \& Ward, J. E. How risks of breast cancer and benefits of screening are communicated to women: analysis of 58 pamphlets. BMJ 317, 263-264 (1998).

11. Domenighetti, G., D'Avanzo, B., Egger, M., Berrino, F., Perneger, T., Mosconi, P. et al. Women's perception of the benefits of mammography screening: population-based survey in four countries. Int. J. Epidemiol. 32, 816-821 (2003).

12. Domenighetti, G., Grilli, R. \& Maggi, J. R. Does provision of an evidence-based information change public willingness to accept screening tests? Health Expect. 3 , 145-150 (2000).

13. Olsen, O. \& Gotzsche, P. C. Screening for breast cancer with mammography. Cochrane Database Syst. Rev. CD001877 (2001).

14. Paci, E. Summary of the evidence of breast cancer service screening outcomes in Europe and first estimate of the benefit and harm balance sheet. J. Med. Screen. 19(Suppl 1), 5-13 (2012). 
15. Independent UK Panel on Breast Cancer Screening. The benefits and harms of breast cancer screening: an independent review. Lancet 380, 1778-1786 (2012).

16. Barratt, A., Jorgensen, K. J. \& Autier, P. Reform of the national screening mammography program in France. JAMA Intern. Med. 178, 177-178 (2018).

17. Lauby-Secretan, B., Scoccianti, C., Loomis, D., Benbrahim-Tallaa, L., Bouvard, V., Bianchini, F. et al. Breast-cancer screening-viewpoint of the IARC Working Group. N. Engl. J. Med. 372, 2353-2358 (2015).

18. European Commission. European guidelines on breast cancer screening and diagnosis. https://ecibc.jrc.ec.europa.eu/recommendations/details/Professional/ decisionaid/decisionaid (2020) Accessed 1 Apr 2020.

19. Gotzsche, P. C. \& Jorgensen, K. J. Screening for breast cancer with mammography. Cochrane Database Syst. Rev. CD001877 (2013).

20. Stacey, D., Legare, F., Lewis, K., Barry, M. J., Bennett, C. L., Eden, K. B. et al. Decision aids for people facing health treatment or screening decisions. Cochrane Database Syst. Rev. 4, CD001431 (2017).

21. Roberto, A., Colombo, C., Candiani, G., Giordano, L., Mantellini, P., Paci, E. et al. Personalised informed choice on evidence and controversy on mammography screening: study protocol for a randomized controlled trial. BMC Cancer 17, 429 (2017).

22. Hersch, J., Barratt, A., Jansen, J., Irwig, L., McGeechan, K., Jacklyn, G. et al. Use of a decision aid including information on overdetection to support informed choice about breast cancer screening: a randomised controlled trial. Lancet $\mathbf{3 8 5}$, 1642-1652 (2015).

23. Mathieu, E., Barratt, A., Davey, H. M., McGeechan, K., Howard, K. \& Houssami, N. Informed choice in mammography screening: a randomized trial of a decision aid for 70-year-old women. Arch. Intern. Med. 167, 2039-2046 (2007).

24. Mathieu, E., Barratt, A. L., McGeechan, K., Davey, H. M., Howard, K. \& Houssami, N. Helping women make choices about mammography screening: an online randomized trial of a decision aid for 40 -year-old women. Patient Educ. Couns. 81, 63-72 (2010).

25. Marmot, M. G., Altman, D. G., Cameron, D. A., Dewar, J. A., Thompson, S. G. \& Wilcox, M. The benefits and harms of breast cancer screening: an independent review. Br. J. Cancer 108, 2205-2240 (2013).

26. Elwyn, G., O'Connor, A. M., Bennett, C., Newcombe, R. G., Politi, M., Durand, M.-A. et al. Assessing the quality of decision support technologies using the International Patient Decision Aid Standards instrument (IPDASi). PLoS ONE 4, e4705 (2009).

27. Marteau, T. M., Dormandy, E. \& Michie, S. A measure of informed choice. Health Expect. 4, 99-108 (2001)

28. Legare, F., Kearing, S., Clay, K., Gagnon, S., D'Amours, D., Rousseau, M. et al. Are you SURE?: assessing patient decisional conflict with a 4-item screening test. Can. Fam. Physician 56, e308-e314 (2010).
29. Ghanouni, A., Meisel, S. F., Renzi, C., Wardle, J. \& Waller, J. Survey of public definitions of the term "overdiagnosis" in the UK. BMJ Open 6, e010723 (2016).

30. Moynihan, R., Nickel, B., Hersch, J., Doust, J., Barratt, A., Beller, E. et al. What do you think overdiagnosis means? A qualitative analysis of responses from a national community survey of Australians. BMJ Open 5, e007436 (2015).

31. Perez-Lacasta, M. J., Martinez-Alonso, M., Garcia, M., Sala, M., Perestelo-Perez, L., Vidal, $C$. et al. Effect of information about the benefits and harms of mammography on women's decision making: the InforMa randomised controlled trial. PLOS ONE 14, e0214057 (2019).

32. Hoffmann, T. C. \& Del Mar, C. Patients' expectations of the benefits and harms of treatments, screening, and tests: a systematic review. JAMA Intern. Med. 175, 274-286 (2015).

33. Martinez-Alonso, M., Carles-Lavila, M., Perez-Lacasta, M. J., Pons-Rodriguez, A., Garcia, M. \& Rue, M. Assessment of the effects of decision aids about breast cancer screening: a systematic review and meta-analysis. BMJ Open 7, e016894 (2017).

34. Reder, M. \& Kolip, P. Does a decision aid improve informed choice in mammography screening? Results from a randomised controlled trial. PLOS ONE 12, e0189148 (2017).

35. Burnside, E. S., Sickles, E. A. \& Duffy, S. W. A pragmatic approach to determine components of optimal screening mammography practice. JAMA 315, 1951-1953 (2016).

36. Sunstein, C. R. Choosing not to choose. Duke Law J. 64, 1-52 (2014).

(C) Open Access This article is licensed under a Creative Commons By Attribution 4.0 International License, which permits use, sharing, adaptation, distribution and reproduction in any medium or format, as long as you give appropriate credit to the original author(s) and the source, provide a link to the Creative Commons license, and indicate if changes were made. The images or other third party material in this article are included in the article's Creative Commons license, unless indicated otherwise in a credit line to the material. If material is not included in the article's Creative Commons license and your intended use is not permitted by statutory regulation or exceeds the permitted use, you will need to obtain permission directly from the copyright holder. To view a copy of this license, visit http://creativecommons. org/licenses/by/4.0/.

(c) The Author(s) 2020, corrected publication 2021 